Scientia Agricola

http://dx.doi.org/10.1590/0103-9016-2015-0163

\title{
Determinants of farmers' adaptation to climate change: A micro level analysis in
}

\section{Ghana}

\author{
${\text { Francis Ndamani }{ }^{*} \text { * }}$ Tsunemi Watanabe ${ }^{2}$
}

${ }^{1}$ Kochi University of Technology/Graduate School of

Engineering, 185-1 Miyanokuchi - Tosayamada -782-0003

- Kami City, Kochi - Japan.

2Kochi University of Technology/School of Economics and

Management.

${ }^{*}$ Corresponding author <176010t@gs.kochi-tech.ac.jp>

Edited by: Paulo Cesar Sentelhas

\begin{abstract}
This study analyzed socio-economic factors that influence farmers' adaptation to climate change in agriculture. Perceptions regarding long-term changes in climate variables and the rate of occurrence of weather extremes were also investigated. Additionally, farmers' perceived barriers to the use of adaptation practices were identified and ranked. A total of 100 farm-households were randomly selected from four communities in the Lawra district of Ghana and data were collected through semi-structured questionnaires, focused group discussions and field observations. A logistic regression model and weighted average index were used to analyze the data. The results showed that $87 \%$ of respondents perceived a decrease in rainfall amount, while $82 \%$ perceived an increase in temperature over the past 10 years. Results of the weighted average index indicate that dry spell and drought have a higher annual rate of occurrence than flood. Empirical results of the logistic regression model showed that education, household size, annual household income, access to information, credit and membership of farmer-based organization are the most important factors that influence farmers' adaptation to climate change. The main constraints on adaptation include unpredictability of weather, high farm input cost, lack of access to timely weather information and water resources. The policy implication of this study is that governments should mainstream barriers to, and choice factors of, adaptation practices to climate change related projects and programs.

Keywords: perceptions, socio-economic, agriculture, climate effects
\end{abstract}

\section{Introduction}

Based on the scope of the impact of climatic variability observed over the last three or four decades, the West African sub-region is generally acknowledged to be one of the areas most vulnerable to the vagaries of climate change (IPCC, 2007). Empirical studies have shown that high temperatures have resulted in reduced crop yield in Ghana (Stephens, 1996; and Stutley, 2010). In recent times, the increasing incidence of droughts, late rains, floods, decreasing annual precipitation and increasing temperatures in the Northern Region, Ghana (Yengoh et al., 2010; Stanturf et al., 2011) have become a major concern. In view of this, farmers need to use adaptation practices in order to cope with the effects of climate change. Studies have shown that without adaptation to climate change, farmers will become more vulnerable and agricultural production will be severely affected (Smit and Skinner, 2002). Adaptation lessens adverse effects and takes advantage of benefits of changes in climate variables. Earlier studies show that irrigation, improved crop varieties, crop diversification, farm diversification, change of planting dates and income generating activities are among the adaptation practices most frequently deployed by farmers (Maddison, 2006; Uddin et al., 2014). Although smallholder farmers are likely to be seriously affected by the effects of climate change owing to their lack of capacity to adequately adapt, research shows that only a minority of them take advantage of adaptation options (Fosu-Mensah et al., 2012). As such, a clear understanding of the factors that influence farmers' adaptation decisions is essential to the designing of appropriate policies to promote effective adaptation in the agricultural sector (Mabe et al., 2014).

Previous studies have reported that farmers' adaptation to climate change is determined by factors such as education, age, farming experience, gender, access to extension, credit, markets, farm income and farm size (Deressa et al., 2011; Gbetibouo, 2009; Nhemachena and Hassan, 2007). This notwithstanding, current investigations on adaptation to climate change are being conducted, but on a continental and regional scale and need to be downscaled to accommodate realities at the farmer level. This study, therefore, hypothesized that household size, gender, education, farm size, access to credit, and membership to farmer-based organizations exert significant influence on adaptation to climate change at the farmer level. Based on this scenario, the aim of this study was to identify socio-economic factors which influence farmers' adaptation to climate change in Lawra district of Ghana.

\section{Materials and methods}

\section{Study area and survey design}

The study was conducted in Lawra district of Ghana, located in the Guinea Savannah agro-ecological zone. It lies in the north western corner of the Upper West Region in Ghana between longitude $2^{\circ} 25 \mathrm{~W}$ and $2^{\circ} 45 \mathrm{~W}$ and latitude $10^{\circ} 20$ and $11^{\circ} 00$. The district experiences two distinct seasons - the dry season (November to April) and the rainy season (May to October). The mean annual temperature ranges from 27 to $36^{\circ} \mathrm{C}$ while mean annual 
rainfall is between 900 and $1,000 \mathrm{~mm}$ and is concentrated into one season. The vegetation is characterized by stunted trees, shrubs and short grasses. Most common trees in the district consist of drought and fire resistant trees such as the shea, baobab, dawadawa, and acacia. The geographical location of Lawra district on the map of Ghana is represented by the red zone in Figure 1.

Agriculture is the mainstay of the district's economy with over $80 \%$ of the population engaged in farming (GSS, 2012). Other livelihood activities of the people include pito (local beer) brewing, charcoal burning, petty trading and small-scale livestock rearing. The limited number of dams and dug-outs in the district makes it difficult for farmers to undertake irrigation farming. The decision to select Lawra district was based on recent incidences of delayed onset of rains, dry spell, droughts and floods during the crop production season. Other reasons included data accessibility and a recommendation from the Ministry of Food and Agriculture.

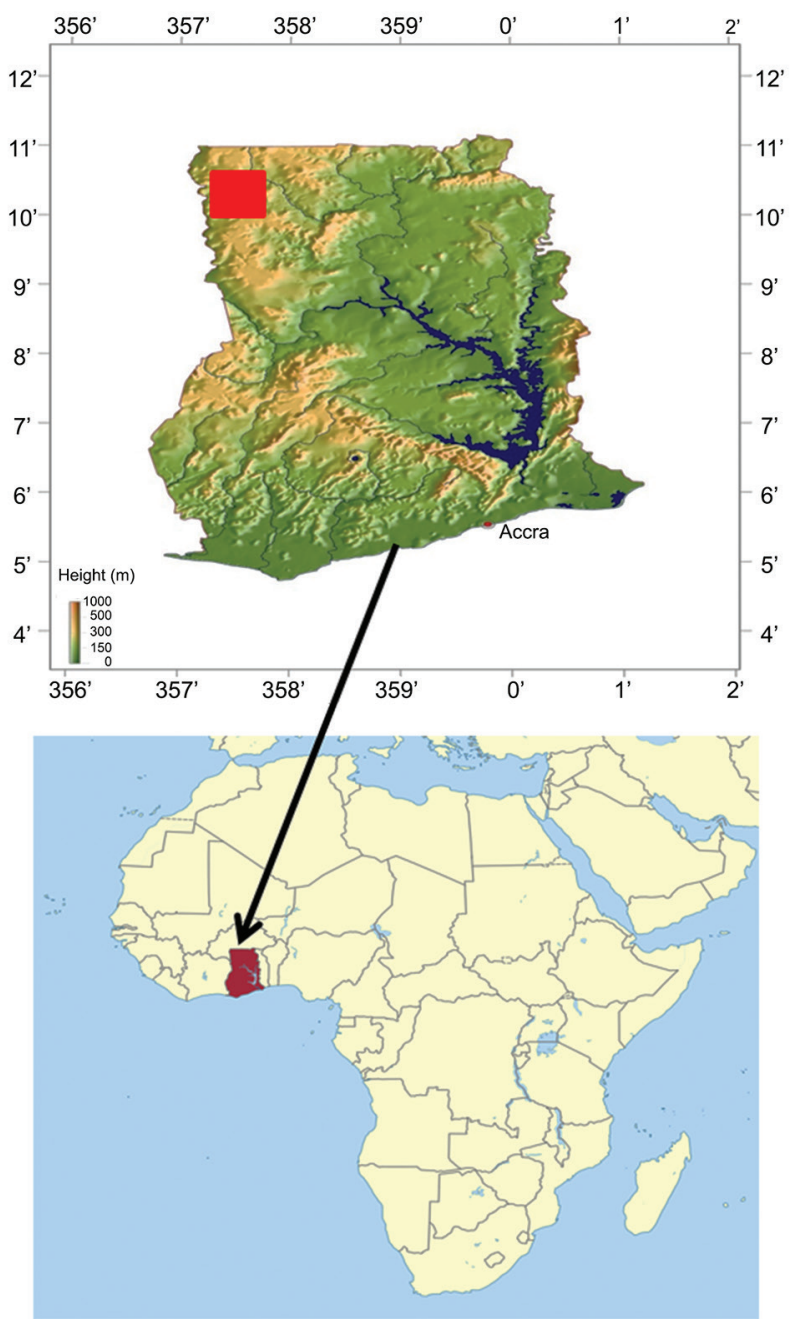

Figure 1 - Location of Lawra district on the map of Ghana (GinkgoMaps-project) and Africa (Google maps, 2015).
Data used in this study were collected from four communities in Lawra district (i.e. Brifo-Chaa, Kalsagri, Methuo and Oribili). Socio-economic household surveys and focus group discussions (FGDs) were conducted in all four communities in November, 2014. Also, face-to-face interviews with key stakeholders were conducted. A total of 100 farmer households were interviewed using semi-structured questionnaires. Twenty-five households were randomly selected from each community and the household heads were individually interviewed. The FGDs were held to double check the household survey data. The participants included community leaders, men, women, youth and children. The discussions in each community focused on perceptions regarding climate and agro-ecological changes, possible effects on agriculture, adaptation practices currently being applied, barriers to adaptation and household characteristics.

\section{Statistical analysis}

A statistical package for social science (SPSS) was used to analyze the data. Percentages, frequencies and means were used to represent farmers' perceived long-term changes in temperature and rainfall and barriers to the use of adaptation practices by farmers. A weighted average index (WAI) analysis has previously been applied to assess farmer-perceived important adaptation strategies in Bangladesh and barriers of adaptation to climate change in Nepal (Uddin et al., 2014; Devkota et al., 2014). In this study, the WAI was used to rank the effects of climate change on crop performance, environment, households' socio-economy and psychological threats. Similarly, the WAI was applied to rank farmer-perceived rate of occurrence of weather extremes (i.e. dry spell, drought and flood). Respondents were asked to score the weather extremes based on a 0-2 Likert scale (i.e in terms of 'high', 'moderate' and 'low'l. The WAI was then estimated using the formula below.

$$
\begin{aligned}
& \mathrm{WAI}=\frac{F_{2} W_{2}+F_{1} W_{1}+F_{0} W_{0}}{F_{2}+F_{1}+F_{0}} \\
& \mathrm{WAI}=\frac{\sum F_{i} W_{i}}{\sum F_{i}}
\end{aligned}
$$

where: $F=$ frequency; $W=$ weight of each scale; $i=$ weight $(2=$ high occurrence; $1=$ moderate occurrence and $0=$ low occurrence)

\section{Empirical model}

The dependent variable in this study is whether a household has 'adapted' or 'not adapted' any adaptation practices to climate change. Based on discussions with MOFA staff, review of the literature and field observations, the adaptation practices identified included improved crop varieties (drought-tolerant and early maturing crops), crop diversification (mixed cropping and crop rotation), farm diversification (mulching, composting, 
ridging and terracing), change in planting date, income generating activities, irrigation practice (dry season gardening) and agroforestry. Adaptation is the dependent dummy variable. To determine the dummy, a value of ' 1 ' was assigned to those households that had adopted at least one of the adaptation options and ' 0 ' for those that had not adopted. Independent variables included gender, education, farming experience, household size, farm size, annual household income, access to credit, information, subsidies, membership of farmer-based organizations (FBOs), markets and extension services (Table 1).

The logistic regression model was used to identify the factors that determine farmers' adaptation to climate change. Previous research findings have shown that logit models are the most appropriate econometric models to apply to the evaluation of qualitative dependent variables that have dichotomous groups (i.e. 'adapted' and 'not adapted') while the independent variables are categorical, continuous and dummy (Long and Freese, 2006). These models are commonly and widely used since they guarantee that the estimated probability increases lie within the range of 0 to 1 and display a sigmoid curve conforming to the theory of adoption. This study used the functional form of the logistic regression model, presented by Agresti (1996). In this model, the dependent variable becomes the natural logarithm of the odds when a positive choice is made:

$\ln \left\{\mathrm{P}_{\mathrm{x}} /\left(1-\mathrm{P}_{\mathrm{x}}\right)\right\}=\beta_{0}+\beta_{1} \mathrm{X}_{1 \mathrm{i}}+\beta_{2} \mathrm{X}_{2 \mathrm{i}}+\ldots .+\beta_{\mathrm{k}} \mathrm{X}_{\mathrm{ki}}$

where: $\mathrm{P}_{\mathrm{x}}=$ probability of adaption; $\left(1-\mathrm{P}_{\mathrm{x}}\right)=$ probability of non-adaption; $i=i^{\text {th }}$ observation in the sample; $\beta_{1}, \beta_{2} \ldots$ $\beta_{\mathrm{k}}=$ regression coefficients of the explanatory variables; $\mathrm{X}_{1}$, $\mathrm{X}_{2} \ldots \ldots . \mathrm{X}_{\mathrm{k}}=$ explanatory variables; $\beta_{0}=$ constant term.

\section{Results and Discussion}

\section{Farmer-perceived long-term changes in climate variables}

Results of the study showed that $82 \%$ of respondents perceived an increase while $6 \%$ perceived a decrease in temperature trend over the past 10 years (Table 2). Also, $9 \%$ of farmers perceived no change in temperature while $3 \%$ could not indicate if there was a longterm temperature change or not. As regards rainfall, an overwhelming majority of farmers $(87 \%)$ perceived a decrease in the precipitation trend over the past 10 years (Table 2), whereas $5 \%$ of respondents perceived an increase and $6 \%$ perceived no change in precipitation. The results also showed that $2 \%$ of farmers did not know if there was a change in precipitation or not.

Table 1 - Definition of variables used in the study in Lawra district of Ghana $(\mathrm{N}=100)$.

\begin{tabular}{|c|c|}
\hline Variable & Measurement \\
\hline Adaptation & 1 =adapted; 2 =not adapted (dummy variables) \\
\hline Age & $1=15-34 ; 2=35-54 ; 3=55$ and above \\
\hline Education & $1=$ literate; $0=$ =illiterate \\
\hline Gender & $1=$ Female; $0=$ Male \\
\hline Farming experience & Number \\
\hline Household size & Number \\
\hline Farm size & Hectares \\
\hline Annual household income & Amount \\
\hline Rainfall pattern & $0=$ decreasing; 1 =increasing; $2=$ stable; $3=$ don't know \\
\hline Temperature pattern & $0=$ decreasing; 1 =increasing; $2=$ stable; $3=$ don't know \\
\hline Drought & $1=$ Yes; $0=$ No \\
\hline Flood & $1=$ Yes; $0=$ No \\
\hline Dry spell & $1=$ Yes; $0=$ No \\
\hline Access to weather information & $1=$ Yes; $0=$ No \\
\hline Market access & $1=$ Yes; $0=$ No \\
\hline Access to loan/credit facilities & $1=$ Yes; $0=$ No \\
\hline Access to agricultural subsidies & $1=$ Yes; $0=$ No \\
\hline Access to agric. Extension services & $0=4$ days; $1=$ less than 4 days; $2=$ more than 4 days \\
\hline Membership of farmer-based organization (FBO) & $1=$ Yes; $0=$ No \\
\hline Use of adaptation practices & $1=$ Yes; $0=$ No \\
\hline Improved crop varieties & $1=$ Yes; $0=$ No \\
\hline Crop diversification & $1=$ Yes; $0=$ No \\
\hline Farm diversification & $1=$ Yes; $0=$ No \\
\hline Change of planting date & $1=$ Yes; $0=$ No \\
\hline Income generating activities & $1=$ Yes; $0=$ No \\
\hline Agroforestry practice & $1=$ Yes; $0=$ No \\
\hline Irrigation & $1=$ Yes; $0=$ No \\
\hline
\end{tabular}


Results of the focus group discussions showed that farmers attributed the perceived trend of increasing temperature to decreasing preprecipitation. Farmers also attributed the perceived trend of decreasing rainfall to factors such as deforestation, bushfires and ancestral curses. The results are in line with findings of previous studies reported in Southern Ghana, Nigeria, Senegal and Southern Africa which showed that the majority of farmers have perceived long-term changes in climate variables (Fosuh-Mensah et al., 2012; Apata, 2011; Mertz et al., 2009; and Nhemachena and Hassan, 2007, respectively).

\section{Perceived occurrence of weather extremes}

The results of farmers' perceptions regarding occurrences of weather extremes are presented in Table 3. Farmers generally perceive weather extremes in terms of dry spells, drought and floods. The rate of occurrence of dry spells was ranked highest by respondents (WAI $=1.88)$. Drought and flood occurrences were ranked $2^{\text {nd }}$ and $3^{\text {rd }}$ respectively $($ WAI $=0.53$ and WAI $=0.34$ ) Same results were obtained during the focus group discussions. Farmers revealed that unlike floods, dry spells occur every year during the crop production season. The respondents claimed that the frequency and severity of floods is decreasing due to decreasing rainfall trend. On the other hand, farmers indicated that the frequency and severity of drought is beginning to increase in recent times. Similar findings were reported in the Wa West District of Ghana where farmers perceived higher frequency and severity of drought than floods (Kusakari et al., 2014). In Uganda however, farmers were reported to have perceived a higher rate of occurrence of flood than drought (Okonya et al., 2013).

Table 2 - Farmers' perception of long-term changes in climate variables $(\mathrm{N}=100)$ in Lawra district of Ghana.

\begin{tabular}{lc}
\hline Variables & \% of Respondents \\
\hline Temperature & 3 \\
Don't know & 6 \\
Decreasing & 9 \\
Stable & 82 \\
Increasing & \\
Precipitation & 2 \\
Don't know & 5 \\
Increasing & 6 \\
Stable & 87 \\
Decreasing & \\
\hline
\end{tabular}

Table 3 - Rate of occurrence of weather extremes $(\mathrm{N}=100)$ in Lawra district of Ghana.

\begin{tabular}{|c|c|c|c|c|c|}
\hline \multirow{2}{*}{ Variables } & \multicolumn{3}{|c|}{ Ranking of weather extremes } & \multirow{2}{*}{ WAI } & \multirow{2}{*}{ Rank } \\
\hline & High & Moderate & Low & & \\
\hline Dry spell & 88 & 12 & 0 & 1.88 & 1 \\
\hline Drought & 10 & 33 & 57 & 0.53 & 2 \\
\hline Flood & 5 & 20 & 75 & 0.30 & 3 \\
\hline
\end{tabular}

Farmer-perceived effects of climatic change on agriculture

Generally, rural farmers perceive effects of climate change on agriculture in terms of poor crop performance, environmental degradation, socio-economic challenges and psychological threats. With a WAI value of 2, poor crop performance was perceived to be the highest effect of climate change on rural agriculture (Table 4). Socio-economic threats and environmental degradation were ranked $2^{\text {nd }}$ and $3^{\text {rd }}$ with WAI values of 1.45 and 1.39, respectively. The respondents also perceived and ranked psychological threats as effects of climate change (WAI $=1.30$ ).

Results of the focus group discussions showed that dry spells and droughts generally cause wilting and drying up of crop plants. These culminate into poor crop development and low yields. The farmers claimed that socio-economic effects of climatic change included outmigration, indebtedness, food shortage and low household incomes. The climatic change related psychological effects identified by farmers included stress, depression and suicides. This is likely the case because farmers' inability to pay back farm resources borrowed from colleague farmers and relatives in the event of a climate-related crop failure can cause psychological trauma. Low incomes and food shortages can also lead to depression, sicknesses and deaths in farm households. The revelation in this study that farmers link psychological threats to climate change is intriguing since it appears no studies as yet have reported similar findings.

\section{Farmers' adaptation practices and reasons for adoption}

About $67 \%$ of farmers who perceived climate change have used adaptation practices. The results of the adaptation measures being used by farmers are shown in Table 5. A slim majority of respondents (51\%) use crop diversification strategies in response to climatic variability. Changing the planting date was chosen by $22 \%$ while improving crop varieties were chosen by $12 \%$. Farmers also use farm diversification measures $(6 \%)$, income generating activities $(6 \%)$ and irrigation $(2 \%)$ to mitigate the effects of climate change on their farming activities. About $1 \%$ of the respondents also undertake agroforestry.

As regards reasons for adaptation, an overwhelming majority (95\%) of respondents use adaptation measures to cope with dry spell effects on crop plants (Table 6). Also, $94 \%$ and $75 \%$ of farm households

Table 4 - Farmer-perceived effects of climate change on agriculture $(\mathrm{N}=100)$ in Lawra district of Ghana.

\begin{tabular}{lccccccc}
\hline \multirow{2}{*}{ Effect variable } & \multicolumn{3}{c}{ Ranking of extremes } & \multirow{2}{*}{ WAl } & Rank \\
\cline { 2 - 6 } & High & Moderate & Low & No & & \\
\hline Poor crop performance & 100 & 0 & 0 & 0 & 2.00 & 1 \\
Socio-economic challenges & 54 & 37 & 9 & 0 & 1.45 & 2 \\
Environmental degradation & 45 & 49 & 6 & 0 & 1.39 & 3 \\
Psychological threats & 50 & 30 & 12 & 8 & 1.30 & 4 \\
\hline
\end{tabular}


Table 5 - Adaptation practices being used by farmers $(\mathrm{N}=67)$ in Lawra district of Ghana.

\begin{tabular}{lcl}
\hline Adaptation practices & \% of respondents & \multicolumn{1}{c}{ Actual adaptation measures } \\
\hline Crop diversification & 51 & Crop rotation and mixed cropping \\
Change planting date & 22 & \\
Improved crop varieties & 12 & Drought-tolerant and early maturing varieties \\
Farm diversification & 6 & Reduce farm size and composting/mulching \\
Income generating activities & 6 & Petty trading and 'pito' brewing \\
Irrigation & 2 & Dry season gardening \\
Agroforestry & 1 & Tree planting \\
\hline
\end{tabular}

Table 6 - Reasons for adaptation to climatic change $(\mathrm{N}=67)$ in Lawra district of Ghana.

\begin{tabular}{lccc}
\hline Reasons for adaptation & \% of respondents & Mean & Std. Deviation \\
\hline Cope with flood & 34 & 0.59 & 0.494 \\
Improve soil fertility & 74 & 0.84 & 0.367 \\
Improve crop production & 75 & 0.64 & 0.483 \\
Cope with drought & 94 & 0.99 & 0.103 \\
Cope with dry spell & 95 & 0.96 & 0.202 \\
\hline
\end{tabular}

adapted to cope with drought effects and improve crop production, respectively. The results also showed that adaptation practices were adopted by $74 \%$ of respondents to improve soil fertility and $34 \%$ to cope with the effects of floods. Results of the FGDs showed that farmers use drought-tolerant and early maturing varieties and change of planting date to adapt to dry spells, droughts and floods. Farmers also use crop rotation and mixed cropping strategies to reduce effects of dry spell on crop plants. Some of the farmers claimed that they used composting and mulching to conserve soil moisture and improve soil fertility so as to increase their crop production. The FGDs also revealed that farmers adopted terracing and ridging methods to reduce the effects of floods.

\section{Factors influencing farmers' selection of adapta- tion practices}

Results of the logistic regression model of determinants of adaptation to climate change are presented in Table 7. Prior to the analysis, the contingency coefficient test was applied to identify and omit independent variables that are strongly correlated to each other. Thus, age of household head, and agricultural subsidies were removed due to their strong co-linearity with farming experience and agricultural credit, respectively. Access to agricultural extension services was also removed because of its weak correlation with adaptation.

The study results showed that education was positive and significantly related to farmers' decision to adapt to climate change. Previous studies have shown that there is a positive relationship between educational level of the household head and adoption of improved technologies (Igodan et al., 1990). This implies that, farmers with higher levels of education are more likely to use improved technologies in order to adapt to climate
Table 7 - Estimated results of logistic regression model $(\mathrm{N}=100)$ in the Lawra district of Ghana.

\begin{tabular}{llll}
\hline Variable & Coefficient & Std. Error & $p$ Value \\
\hline Intercept & 8.419 & 2.561 & 0.001 \\
GEND & -0.316 & 1.73 & 0.855 \\
FRMINEXP & -1.829 & 1.196 & 0.126 \\
EDU & $7.363^{*}$ & 2.765 & 0.008 \\
HHSZ & $5.48^{*}$ & 2.134 & 0.010 \\
FRMSZ & $-3.221^{*}$ & 1.625 & 0.047 \\
HHINC & 1.627 & 1.289 & 0.207 \\
WINFOACC & $4.572^{*}$ & 1.612 & 0.005 \\
MRKTACC & 0.635 & 1.51 & 0.674 \\
CREDACC & $3.405^{*}$ & 1.568 & 0.030 \\
FBOMEMB & 1.672 & 1.405 & 0.234 \\
Pseudo R & \multicolumn{4}{c}{0.754} \\
\hline *indicates significant level at 5 \%; GEND = Gender; FRMINEXP = Farming \\
experience; EDU = Education; HHSZ = Household size; FRMSZ = Farm size; \\
HHINC = Household income; WINFOACC = Weather information access; \\
MRKTACC = Market access; CREDACC = Access to credit facilities; FBOMEMB \\
= Membership to farmer-based organization.
\end{tabular}

change. This is particularly so because educated farmers are more knowledgeable due to their ability to access information pertaining to climate change and adaptation options.

The results also showed that the probability of adaptation rises with increased access to information. This implies that farmers with access to timely weather information and other extension services are more likely to adapt to climatic change. Similar findings have been reported in Nepal and Southern Africa (Tiwari et al., 2014; Nhemachena and Hassan, 2007).

In addition, results of the study indicated that the likelihood of adaptation to climate change was higher with large household size than with small households. Similarly, earlier investigations have shown that the visible tendency of larger households to adapt to climate change is probably due to their higher endowment of labor (Oyekale and Oladele, 2012).

Furthermore, the study results showed that the probability of adaptation to climate change rises with increased access to credit facilities. This result is consistent with previous findings that access to credit is an important variable which commonly has a positive effect on adaptation behavior (Caviglia-Harris, 2002), and thus adaptation to climate change (Fosu-Mensah et al., 2012). 
Household income was also positively related to adaptation. This result is in line with previous findings that showed that wealthier farmers are more likely to use adaptation practices in response to climate change than poor farmers (Gbetibuou, 2009). It is also been reported that per capita income has a positive influence on farmers' adaptation decisions (Nhechema and Hassan, 2007).

Results of the study also revealed a positive relationship between membership to farmer-based organization (FBOs) and adaptation to climatic change. This is consistent with earlier research findings in Nepal and Bangladesh that showed that farmers belonging to cooperative organizations have higher likelihood of using adaptation practices due to their capacity to share information - discuss problems, share ideas and take collaborative decisions (Tiwari et al., 2014; Uddin et al., 2014). Also, the results revealed that access to market is positively related to adaptation. Results of the focus group discussions showed that farmers' decision to adopt crop diversification was based on availability of market. This result is consistent with findings reported in Southern Africa (Nhechema and Hassan, 2007).

On the other hand, the probability of adaptation decreases with farming experience. The FGDs revealed that farmers with the greatest farming experience are older persons. This implies that the likelihood of adaptation to climate change decreases in older farmers. This finding is confirmed by results of previous studies which showed that older farmers generally are lacking in interest and incentive to adapt to climate change (Uddin et al., 2014; Shiferaw and Holden, 1998). This notwithstanding, studies in Ethiopia have also shown a positive relationship between number of years of experience in agriculture and adoption of improved agricultural technologies (Kebede et al., 1990). Furthermore, the estimated results showed that the probability of adaptation is higher with small farm sizes and lower with large farm sizes. The FGD results revealed that adaptation investment in adaptation (i.e. irrigation facilities, improved seeds and fertilizer) for large farm sizes was expensive. A number of previous studies have also reported similar findings (Acquah, 2011).

Table 8 - Constraints on use of adaptation practices $(N=100)$ in Lawra district of Ghana.

\begin{tabular}{lc}
\hline Constraints to adoption & \% of respondents \\
\hline Unpredictability of weather & 21.5 \\
High cost of farm inputs & 20.2 \\
Lack of access to timely weather information & 17.8 \\
Lack of access to water resources (e.g. dams) & 14.4 \\
Lack of access to credit facilities & 8.1 \\
Lack of access to agricultural subsidies & 6.4 \\
Poor soil fertility & 4.2 \\
Limited access to agricultural extension officers & 2.4 \\
Limited access to agricultural markets & 2.1 \\
Inadequate farm labor & 1.6 \\
Limited farm size & 1.3 \\
\hline
\end{tabular}

The results also revealed that male farmers are more likely to use adaptation measures against climate change than female farmers. This finding is confirmed by the results of previous studies which showed that in Sub-Saharan Africa, female household heads have lower levels of education, less access to markets and credit and other inputs (Blackden and Wodon, 2006), Thus, they are less likely to meet the investment demands of climate change adaptation. Similar studies have also revealed that women are less able to diversify income sources and adapt to climate change because of other domestic responsibilities and less control of financial resources (Röhr, 2007).

\section{Barriers to use of adaptation practices in agricul- ture}

The results of farmers' perceived constraints on the use of adaptation practices are shown in Table 8. The results of the FGDs confirmed that unpredictability of weather, high farm input cost, lack of access to timely weather information and lack of access to water resources are the most important barriers to farmers. Lack of credit facilities and agricultural subsidies, and poor soil fertility were considered as moderate constraints while limited numbers of agricultural extension officers, agricultural markets, and limited farm size and farm labor were generally considered to be less important barriers.

Unpredictability of weather coupled with limited information from weather forecasts makes it difficult for farmers to plan ahead. The FGDs revealed that lack of agricultural credit and subsidies limit the farmers' ability to obtain the resources required to deploy appropriate adaptation practices against climate change. Farmers claimed that this situation was compounded by the high farm input cost. Similar findings were reported in Southern Africa where smallholder farmers are unable to meet the transaction cost of adaptation measures due to lack of credit facilities (Nhemachena and Hassan, 2007; Deressa et al., 2009). The FGDs also revealed that the absence of water resources (e.g. dams and dug-outs) makes irrigation practice impossible.

\section{Issues for further studies}

This study applies a static model to investigate the factors influencing adaptation to climate change in agriculture. As such, the model, for example, does not explain how different wealth categories of farmers take decisions on adaptation. Therefore, to make it clearer as to whether wealthier farmers or poorer farmers are more likely to adapt to climate change, a dynamic model should be applied in future investigations.

\section{Conclusion}

This study identified a number of factors that determine farmers' adaptation to climatic change. These factors include education, household size, household income, access to information, credit and markets, and 
membership to FBOs. Also, the study identified the unpredictability of weather, high farm input cost, lack of access to timely weather information and limited access to water resources as the most critical barriers to adaptation.

In light of the above, this study concludes that governments and development partners should mainstream the determining factors of adaptation and barriers to adaptation into climate change related policies, projects and programs. Accessibility to timely weather information and formation of famer-based organizations (FBOs) should be prioritized to help farmers improve their information sharing and decision-making processes. There is also the need for construction of dams and dug-outs so that farmers can undertake dry season gardening and irrigation farming. The Ghana Meteorological Agency should be adequately trained and resourced to collect and disseminate accurate and timely weather information. Additionally, government should ensure that flexible terms of agricultural credits are made accessible to farmers so that they can meet the financial demands of adaptation.

Furthermore, this study revealed that the rate of occurrence of dry spells and drought is higher than flood. Government should, therefore, boost the capacity of research scientists and agricultural staff to develop and promote appropriate and effective technologies (e.g. drought-tolerant and early maturing crop varieties) to help farmers adapt to these extreme weather events.

\section{References}

Acquah, H.D. 2011. Farmers' perception and adaptation to climate change: a willingness to pay analysis. Journal of Sustainable Development in Africa 13: 150-161.

Agresti, A. 1996. An Introduction to Categorical Data Analysis. John Wiley, New York, NY, USA.

Apata, T.G. 2011. Factors influencing the perception and choice of adaptation measures to climate change among farmers in Nigeria: evidence from farm households in southwest Nigeria. Environmental Economics 2: 74-83.

Blackden, C.M.; Wodon, Q. 2006. Gender, Time Use and Poverty in Sub-Saharan Africa.World Bank: Washington, DC, USA. (World Bank Working Papers, 73). Caviglia-Harris, J. 2002. Sustainable Agricultural Practices in Rondônia, Brazil: Do Local Farmer Organizations Impact Adoption Rates? Department of Economics and Finance. Salisbury University, Salisbury, MD, USA.

Deressa, T.T.; Hassan, R.M.; Ringler, C.; Alemu, T.; Yesuf, M. 2009. Determinants of farmers' choice of adaptation methods to climate change in the Nile basin of Ethiopia. Global Environmental Change 19: 248-255.

Deressa, T.T.; Hassan, R.M.; Ringler, C. 2011. Perception of and adaptation to climate change by farmers in the Nile basin of Ethiopia. The Journal of Agricultural Science 149: 23-31.

Devkota, R.P.; Cockfield, G.; Maraseni, T.N. 2014. Perceived community-based flood adaptation strategies under climate change in Nepal. International Journal of Global Warming 6: 113-124.
Fosu-Mensah, B.Y.; Vlek, P.L.G.; MacCarthy, D.S. 2012. Farmers' perceptions and adaptation to climate change: a case study of Sekyeredumase district in Ghana. Environment, Development and Sustainability 14: 495-505.

Gbetibouo, G.A. 2009. Understanding Farmers' Perceptions and Adaptations to Climate Change and Variability: The Case of the Limpopo Basin, South Africa. International Food Policy Research Institute, Washington, DC, USA. (IFPRI Discussion Paper, 00849).

Ghana Statistical Service [GSS]. 2012. Population and housing census: GinkgoMaps Project. Africa: maps of Ghana. Available at: http://www.ginkgomaps.com. [Accessed Jun. 19, 2015]

Igodan, C.O.; Ohoji, P.E.; Ekpere, J.A. 1990. Factors associated with the adoption of recommended practices for maize production in the Lake Basin of Nigeria. Agricultural Administration and Extension 29: 149-156.

Intergovernmental Panel on Climate Change [IPCC]. 2007. Climate change: the scientific basis. Available at: http://www. ipcc.ch/. [Accessed Mar. 7, 2015]

Kebede Y.; Gunjal, K.; Coffin, G. 1990. Adoption of new technologies in Ethiopian agriculture: the case of TeguletBulga District, Shewa Province. Agricultural Economics 4: 27-43.

Kusakari, Y.; Asubonteng, K.O.; Jasaw, G.S.; Dayour, F.; Dzivenu, T.; Lolig, V.; Donkoh, S.A.; Obeng, F.K.; Gandaa, B.; KranjacBerisavljevic, G. 2014. Farmer-perceived effects of climate change on livelihoods in Wa West District, Upper West region of Ghana. Journal of Disaster Research 9: 516-528.

Long, S.T.; Freese, J. 2006. Regression Model for Categorical Dependent Variables Using Stata. Stata, Collage Station, TX, USA.

Mabe, F.N.; Gifty, S.; Samuel, D. 2014. Determinants of choice of climate change adaptation strategies in northern Ghana. Research in Applied Economics 6: 75-94.

Maddison, D. 2006. The perception of and adaptation to climate change in Africa. Centre for Environmental Economics and Policy in Africa, Pretoria, South Africa. (Discussion Paper, 10).

Mertz, O.; Mbow, C.; Reenberg, A.; Diouf, A. 2009. Farmers' perceptions of climate change and agricultural adaptation strategies in rural Sahel. Environmental Management 43: 804816.

Nhemachena, C.; Hassan, R. 2007. Micro-Level Analysis of Farmers' Adaptation to Climate Change in Southern Africa. International Food Policy Research Institute, Washington, DC, USA. (IFPRI Discussion Paper, 00714).

Okonya, J.S.; Syndikus, K.; Kroschel, J. 2013. Farmers' perceptions of and coping strategies to climate change: evidence from six agro-ecological zones of Uganda. Journal of Agricultural Science 5: 252-263.

Oyekale, A.S.; Oladele, O.I. 2012. Determinants of climate change adaptation among cocoa farmers in southwest Nigeria. ARPN Journal of Science and Technology 2: 154-168.

Röhr, U. 2007. Gender, climate change and adaptation: introduction to the gender dimensions. Available at: http:// www.unep.org/roa/amcen/Projects_Programme/climate_ change/PreCop15/Proceedings/Gender-and-climate-change/ Roehr_Gender_climate.pdf [Accessed Mar. 9, 2015] 
Shiferaw, B.; Holden, S. 1998. Resource degradation and adoption of land conservation technologies in the Ethiopian highlands: case study in Andit Tid, north Shewa. Agricultural Economics 27: 739-752.

Smit, B.; Skinner, M.W. 2002. Adaptations options in agriculture to climate change: a typology. Mitigation and Adaptation Strategies for Global Change 7: 85-114.

Stanturf, A.J.; Warren Jr., M.L.; Charnley, S.; Polasky, S.C.; Goodrick, S.L.; Armah, F.; Nyako, Y.A. 2011. Ghana climate change vulnerability and adaptation assessment. Available at: http://www.encapafrica.org/documents/biofor/Climate\%20 Change\%20Assessment_Ghana_\%20FINAL.pdf. [Accessed Apr. 7, 2015]

Stephens, C.S. 1996. Some empirical evidence of global warming in Ghana. Ghana Journal of Science 31: 31-36.

Stutley, C. 2010. Innovation Insurance Product for the Adaptation to Climate Change Project Ghana (IIPACC): crop insurance feasibility study; Accra. Available at: http://seguros. riesgoycambioclimatico.org/DocInteres/eng/Ghana-CropInsurance.pdf [Accessed Mar. 9, 2015]
Tiwari, K.T.; Rayamajhi, S.; Pokharel, R.K.; Balla, M.K. 2014. Determinants of the climate change adaptation in rural farming in Nepal Himalaya. International Journal of Multidisciplinary and Current Research 2: 2321-3124.

Uddin, M.N.; Bokelmann, W.; Entsminger, J.S. 2014. Factors affecting farmers' adaptation strategies to environmental degradation and climate change effects: a farm level study in Bangladesh. Climate 2: 223-241.

Yengoh, G.T.; Armah, F.A.; Onumah, E.E.; Odoi, J.O. 2010. Trends in agriculturally-relevant rainfall characteristics for small-scale agriculture in northern Ghana. Journal of Agricultural Science 2: 3-16. 